\title{
STABILITAS KIMIA DAN USIA SIMPAN SIRUP PARASETAMOL PADA BERBAGAI SUHU PENYIMPANAN
}

\author{
Iskandar Zulkarnain \\ Fakultas Farmasi Universitas Muslim Indonesia \\ Email : izukaahmad@yahoo.com.
}

\begin{abstract}
Paracetamol syrup used to treat the symptoms of an illness and is often used as a stock. Chemical stability during storage is important to know. This study aims to determine the half-life of paracetamol syrup and store age. Stability testing performed on 4 kinds of paracetamol syrup that is Generic $A$ and $B$, and $C$ and $D$. Each issued its contents syrup $30 \mathrm{ml}$ and stored at room temperature and refrigerator temperature. For comparison there are also groups syrup without treatment. After that stability testing. The method of testing is done by an accelerated stability test that samples stored at $40^{\circ} \mathrm{C}, 50^{\circ} \mathrm{C}$, and $60^{\circ} \mathrm{C}$ for 4 days and then determined the concentration of paracetamol syrup every day. Age store (t90) obtained from the results of the study for paracetamol syrup $A$ generic product without treatment, room temperature and the temperature in the refrigerator is 3.44237, 2.42564 in, 0.66226 years. For paracetamol syrup generic product $B$ without treatment, room temperature and the temperature in the refrigerator is 2.38027, 1.52801 in, 0.34438 years. For paracetamol syrup product patent $C$ without treatment, room temperature and refrigerator temperature is 4.98265 in, 4.09024 in, 3.59095 years. For paracetamol syrup patent product $D$ without treatment, room temperature and refrigerator temperature is $4.14238 \mathrm{in}, 3.44643 \mathrm{in}, 2.70283$ years. So it can be known that paracetamol syrup stored at room temperature more stable
\end{abstract}

Keywords : Chemical Stability, Half-Life, Shelf Age, Paracetamol

\section{PENDAHULUAN}

Parasetamol merupakan derifat asetanilida yang digunakan sebagai analgetik-antipiretik. Parasetamol sebagai obat golongan analgetikantipiretik yang pada saat ini banyak digunakan oleh masyarakat. Parasetamol dianggap sebagai zat antinyeri yang paling aman. Umumnya obat dalam bentuk cair lebih disukai daripada bentuk padat karena mudahnya menelan cairan dan keluwesan dalam pemberian dosis, pemberian lebih mudah untuk memberikan dosis yang relatif sangat besar, aman dan juga mudah diatur penyesuaian dosis untuk anak ( arisandi, 2008 ).

Sirup parasetamol sering digunakan sebagai antipiretik buat anak-anak, bahkan sebagian orang menyediakannya sebagai stok 
dirumah untuk menjaga jika anak mereka demam. Penggunaan sirup parasetamol hanya mengobati gejala, sehingga tidak diminum hingga habis. Hal ini menyebabkan obat masih tersisa banyak dan konsumen cenderung untuk menyimpan sisa dari obat tersebut. Sebagian tetap menyimpan disuhu kamar sebagian lagi menyimpan didalam lemari pendingin.

\section{Keberhasilan pengobatan} tergantung pada kadar zat aktif yang dapat mencapai tempat aksi. Kadar yang kurang dari dosis efektif akan mempersulit penyembuhan penyakit. Hal ini bisa terjadi karena pemberian dosis yang kurang atau karena terjadinya penurunan kualitas obat selama penyimpanan. Dengan demikian kontrol kualitas dan penetapan waktu kadaluwarsa obat sangat diperlukan ( arisandi, 2008 ).

Jalur utama degradasi yang menyebabkan parasetamol tidak stabil adalah peristiwa hidrolisis yang memecah parasetamol menjadi $p$ aminofenol dan asam asetat, dan hal ini dapat terjadi selama penyimpanan obat, sehingga kontrol kualitas dan penetapan waktu kadaluwarsa obat sangat diperlukan, selain itu penting untuk memformulasikan obat sedekat mungkin dengan $\mathrm{pH}$ optimumnya untuk memperoleh sediaan yang lebih stabil selama penyimpanan (Connors, et al.,1986).

Oleh karena itu perlu dilakukan penelitian mengenai stabilitas kimia yaitu dengan menentukan kadar parasetamol untuk mengetahui stabilitas kimianya.utamanya sirup yang telah digunakan sebagian dan disimpan untuk diminum kembali

\section{METODE PENELITIAN}

\section{Alat Dan Bahan}

Adapun alat yang digunakan adalah timbangan, labu takar, spektrofotometer, alat-alat gelas, oven, stopwatch, Parasetamol, air suling, larutan $\mathrm{NaOH} 0,1 \mathrm{~N}$

Adapun bahan yang digunakan adalah sampel sirup parasetamol dipilih dari 4 merek yang berbeda yaitu 2 generik dan 2 merek dagang. Sirup parasetamol yang diambil adalah dengan tahun pembuatan yang sama maksimal 2 tahun setelah pembuatan.

\section{Prosedur Kerja}

\section{Penyiapan Larutan Uji}

Larutan stok parasetamol dibuat dengan konsentrasi 1000 ppm. Kemudian dibuat larutan baku dengan konsentrasi 20, 40, 60, 80 dan 100 ppm. Panjang gelombang maksimum parasetamol ditentukan antara 200$300 \quad \mathrm{~nm}$ menggunakan 
spektrofotometer UV-VIS. Sirup parasetamol sebanyak $1 \mathrm{ml}$ ditambahkan larutan natrium hidroksida $0,1 \mathrm{~N}$, hingga $10 \mathrm{ml}$ kemudian dipipet sebanyak $1 \mathrm{ml}$ ditambahkan air hingga $50 \mathrm{ml}$.

\section{Pelaksanaan Pengujian}

Sirup parasetamol dari 4 merek yang berbeda masing-masing sebanyak 36 botol disimpan selama satu bulan dengan sebelumnya dikelompokkan menjadi 3 kelompok yaitu:

1. Kelompok I tanpa perlakuan masing-masing sebanyak 12 botol.

2. Kelompok II masing-masing sebanyak 12 botol dikeluarkan isinya sebanyak $30 \mathrm{ml}$ kemudian disimpan pada suhu kamar.
3. Kelompok III masing-masing sebanyak 12 botol dikeluarkan isinya sebanyak $30 \mathrm{ml}$ kemudian disimpan pada lemari pendingin

Sirup parasetamol yang telah disimpan selama satu bulan dari masing-masing kelompok pengujian kemudian dimasukkan kedalam oven dengan suhu $40^{\circ} \mathrm{C}, 50^{\circ} \mathrm{C}$, dan $60^{\circ} \mathrm{C}$ selama 4 hari , pada hari ke 1, 2, 3, dan 4, diambil 1 botol dan diukur kadar parasetamol. Kemudian ditentukan orde reaksi dari laju penguraian parasetamol, selanjutnya ditentukan konstanta laju reaksi parasetamol pada suhu $25^{\circ} \mathrm{C}$ dengan menggunakan persamaan Arrhenius. Kemudian menentukan waktu paruh dan usia simpan dari sirup parasetamol.

\section{HASIL PENELITIAN}

Tabel 1. Hasil perhitungan waktu paruh parasetamol

\begin{tabular}{|l|l|l|l|}
\hline \multirow{2}{*}{ Produk } & \multicolumn{3}{|l|}{ Waktu Paruh (Tahun) } \\
\cline { 2 - 4 } & tanpa Perlakuan & Suhu Kamar & Suhu Dingin \\
\hline Generik A & 30.98132 & 21.83080 & 5.96037 \\
\hline Generik B & 21.42241 & 13.75212 & 3.09941 \\
\hline Paten C & 44.84382 & 36.81217 & 32.31856 \\
\hline Paten D & 37.28139 & 31.01787 & 24.32546 \\
\hline
\end{tabular}


Tabel 2 Hasil perhitungan t9o parasetamol

\begin{tabular}{|l|l|l|l|}
\hline \multirow{2}{*}{ Produk } & \multicolumn{2}{|l|}{ t 90\% (Tahun) } \\
\cline { 2 - 4 } & Tanpa Perlakuan & Suhu Kamar & Suhu Dingin \\
\hline Generik A & 3.44237 & 2.42564 & 0.66226 \\
\hline Generik B & 2.38027 & 1.52801 & 0.34438 \\
\hline Paten C & 4.98265 & 4.09024 & 3.59095 \\
\hline Paten D & 4.14238 & 3.44643 & 2.70283 \\
\hline
\end{tabular}

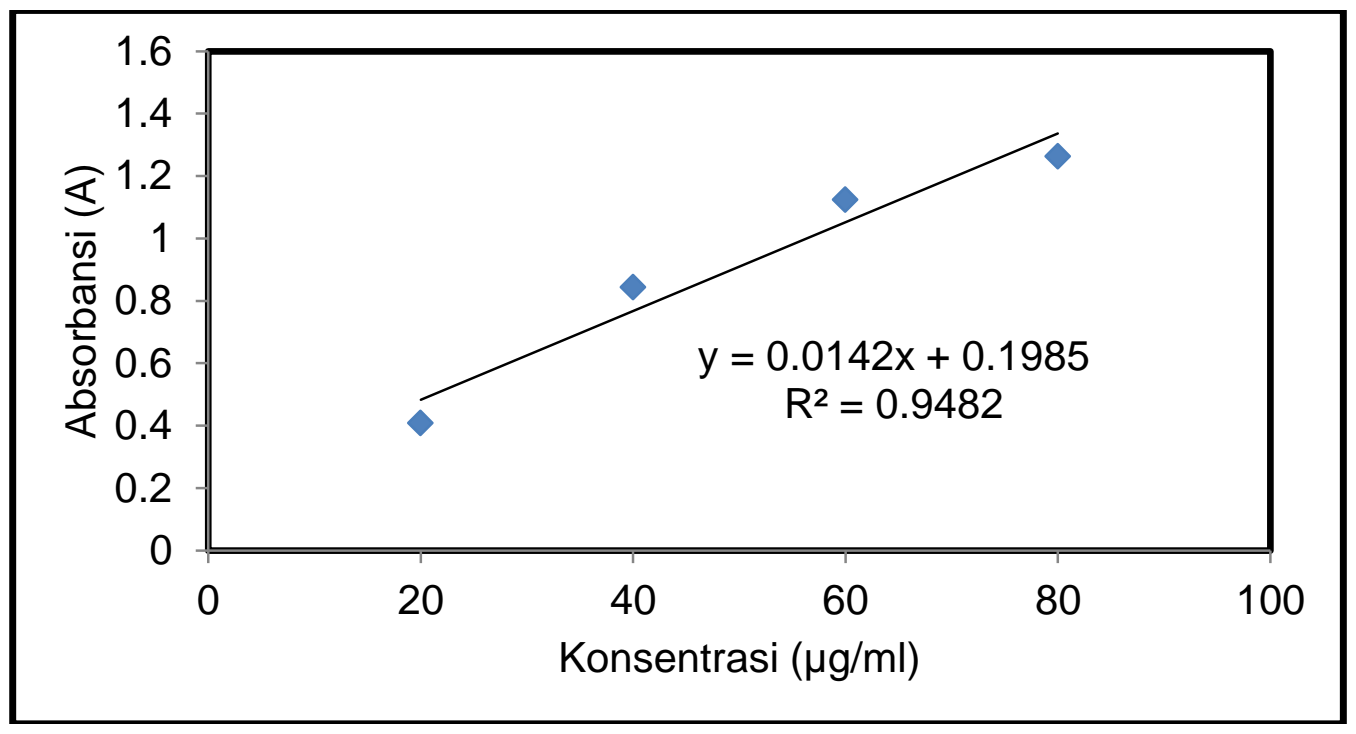

Gambar 1. Kuva baku Parasetamol pada panjang gelombang 290 nm

\section{PEMBAHASAN}

Panjang gelombang maksimum parasetamol yang diperoleh 290nm kemudian dibuat kurva baku yang digunakan untuk menentukan kadar parasetamol dalam sirup parasetamol. Kurva baku dapat dilihat pada gambar 1.

Setelah dilakukan analisis kestabilan dipercepat, diperoleh konsentrasi untuk sirup parasetamol pada suhu $40^{\circ} \mathrm{C}, 50^{\circ} \mathrm{C}$, dan $60^{\circ} \mathrm{C}$ dari 4 produk yaitu generik $A, B$, paten $C$, dan D selanjutnya ditentukan orde rekasi dan diperoleh hasil laju penguraian parasetamol dalam sirup mengikuti orde dua. Selanjutnya ditentukan nilai pada suhu $25^{\circ} \mathrm{C}$ menggunakan persamaan Arrhenius yaitu

$$
\log \mathrm{K}=\log \mathrm{A}-\frac{E a}{2,303 R} \times \frac{1}{T}
$$

dan diperoleh nilai $\mathrm{k}$ pada suhu $25^{\circ} \mathrm{C}$ yaitu 0,00125 hari $^{-1}$ Penentuan waktu paruh $\left(t_{1 / 2}\right)$ diperoleh hasil sesuai tabel 1. Sedangkan usia simpan atau $t_{90}$ diperoleh hasil pada tabel 2. Penelitian 
ini dilakukan untuk mengetahui stabilitas kimia obat sirup parasetamol yang telah digunakan sebagian dan sisanya disimpan pada suhu kamar dan suhu lemari pendingin dengan tujuan untuk menentukan stabilitas kimia dan usia simpan.

Menurut Arisandi (2008), parasetamol merupakan derifat asetanilida yang digunakan sebagai analgetik-antipiretik. Parasetamol sebagai obat golongan analgetikantipiretik yang pada saat ini banyak digunakan oleh masyarakat dan dianggap sebagai zat anti nyeri yang paling aman. Umumnya obat dalam bentuk cair lebih disukai daripada bentuk padat karena mudahnya menelan cairan dan keluwesan dalam pemberian dosis. Pemberian obat lebih mudah walaupun dosisnya relatif sangat besar, aman dan juga mudah diatur, dapat dilakukan penyesuaian dosis untuk anak.

Obat-obat terkadang memiliki struktur kimia yang cukup rumit dan berdasarkan definisinya merupakan senyawa aktif biologi. Sehingga, tidaklah mengherankan jika molekulmolekul reaktif ini mengalami reaksireaksi kimia yang menyebabkan terjadinya dekomposisi dan penguraian molekul sendiri, dan proses ini terjadi segera setelah obat- obatan tersebut disintesis dan diformulasi. Reaksi dekomposisi tersebut kebanyakan menyebabkan obat-obatan menjadi kurang aktif dari yang diharapkan (efikasi rendah) dan yang lebih parah lagi dekomposisi dapat menyebabkan obat menjadi toksik bagi pasien (Cairns, 2008).

Menurut Connors (1986), stabilitas obat adalah derajat degradasi suatu obat dipandang dari segi kimia. Stabilitas obat dapat diketahui dari ada atau tidaknya penurunan kadar selama penyimpanan.

Parasetamol digunakan hanya untuk mengobati gejala, sehingga tidak diminum sampai habis, hal ini menyebabkan obat masih tersisa banyak dan masyarakat cenderung untuk menyimpan sisa dari obat tersebut, tetapi data ilmiah tentang stabilitas sirup parasetamol dan suhu penyimpanannya belum banyak tersedia. Kestabilan kimia sirup parasetamol dapat dilihat dari waktu paruhnya setelah analisis kestabilan dipercepat. Demikian pula dengan usia simpan dapat ditentukan kembali.

Studi ini adalah penelitian eksperimental laboratorium yaitu evaluasi kestabilan dipercepat untuk mengetahui stabilitas sediaan sirup parasetamol dengan menyimpannya 
pada suhu 400C, 500C, dan 600C selama masing-masing 4 kali 24 jam. Dari masing-masing sampel di atas dilakukan replikasi 2 kali dan tiap sampel ditentukan kadar parasetamol yang tersisa setiap 24 jam dengan mengukur serapan menggunakan spektrofotometer UV-Vis.

Parameter yang ditentukan meliputi waktu paruh (t1/2) dan waktu kadaluwarsa (t90). Waktu paruh (t1/2) adalah waktu yang diperlukan untuk separuh reaktan mengalami degradasi, sedangkan waktu kadaluwarsa (t90) adalah waktu yang diperlukan untuk reaktan mengalami degradasi $10 \%$.

Hasil uji stabilitas dipercepat menunjukkan bahwa setiap peningkatan suhu maka nilai rata-rata kadar parasetamol semakin menurun dengan laju peruraian parasetamol yang meningkat. Untuk menentukan laju penguraian parasetamol dalam sirup maka terlebih dahulu ditentukan orde reaksi dari penguraian parasetamol. Hasil penentuan orde reaksi menunjukkan parasetamol dalam sirup mengikuti orde dua. Hasil penentuan laju reaksi menggunakan orde dua menunjukkan bahwa terjadi peningkatan laju reaksi dengan meningkatnya suhu. Sedangkan penentuan laju reaksi pada suhu $25^{\circ}$
C. Hasil perhitungan waktu paruh dan waktu daluarsa dari sirup parasetamol diperoleh hasil Untuk waktu paruh sirup parasetamol produk generik $A$ tanpa perlakuan, A suhu kamar, A suhu dingin adalah 30,98132 tahun, 21,83080 tahun, 5,96037 tahun. Untuk sirup parasetamol produk generik $B$ tanpa perlakuan, B suhu kamar, B suhu dingin adalah 21,42241 tahun, 13,75212 tahun, 3,09941 tahun. Untuk sirup parasetamol produk paten $\mathrm{C}$ tanpa perlakuan, C suhu kamar, C suhu dingin adalah 44,84382 tahun, 36,81217 tahun, 32,31856 tahun. Dan untuk sirup parasetamol produk paten D tanpa perlakuan, D suhu kamar, D suhu dingin adalah 37,28139 tahun, 31,01787 tahun, 24,32546 tahun. sedangkan waktu daluarsa sirup parasetamol produk generik $A$ tanpa perlakuan, A suhu kamar, A suhu dingin adalah 3,44237 tahun, 2,42564 tahun, 0,66226 tahun. Untuk sirup parasetamol produk generik $B$ tanpa perlakuan, B suhu kamar B suhu dingin adalah 2,38027 tahun, 1,52801 tahun, 0,34438 tahun. Untuk sirup parasetamol produk paten $C$ tanpa perlakuan, C suhu kamar, C suhu dingin adalah 4,98265 tahun, 4,09024 tahun, 3,59095 tahun. Dan untuk sirup parasetamol produk paten $D$ tanpa perlakuan, D suhu kamar, D suhu 
dingin adalah 4,14238 tahun, 3,44643 tahun, 2,70283 tahun.

Pada penelitian ini dapat diketahui bahwa sirup parasetamol yang disimpan pada suhu kamar lebih stabil dibandingkan sirup parasetamol yang disimpan pada suhu dingin atau suhu dingin. Dimana konsentrasi parasetamol pada suhu kamar lebih tinggi, tetapi berdasarkan uji statistik dari waktu paruh dan t90 dengan metode ANOVA one way diperoleh bahwa perbedaan waktu paruh dan waktu daluarsa pada ke tiga perlakuan tidak berbeda nyata (non signifikan) pada taraf kepercayaan $95 \%$. Hal ini berarti sirup parasetamol dapat disimpan pada suhu kamar dan suhu dingin.

Selain itu sirup parasetamol yang disimpan pada suhu kamar lebih stabil dibandingkan suhu dingin.

\section{KESIMPULAN}

Sediaan sirup parasetamol baik yang disimpan pada suhu kamar maupun suhu lemari pendingin tetap stabil Suhu penyimpanan tidak mempengaruhi waktu paruh dan usia simpan

\section{DAFTAR PUSTAKA}

Ansel, H.C., Nicholas G.P., Loyd V.A., 1995. Pharmaceutical Dosage Forms and Drug Delivery systems, Sixth edition. A Lea and Febiger Book, Philadelphia.
Arisandi, W, S., 2008. Pengaruh pH Terhadap Stabilitas Sirup Paracetamol, (online) (http://www.scribd.com.diakses 29 maret 2011).

Cairns, D., 2008, Intisari Kimia Farmasi, edisi kedua, diterjemahkan oleh Rini. M. P., EGC, Jakarta.

Connors, K.A., Amidon, G.L. and Stella, V.J., 1986. Chemical Stability of Pharmaceutical. John Willey and Sons, NewYork.

Ditjen POM., 1979, Farmakope Indonesia, edisi III. Departemen Kesehatan Republik Indonesia, Jakarta.

Ditjen POM., 1995, Farmakope Indonesia, edisi IV. Departemen Kesehatan Republik Indonesia, Jakarta.

Lachman, L., Lieberman, H. A., Kanig, J. L.,1994. Teori dan Praktek Farmasi Industri. Edisi ketiga, diterjemahkan oleh: Suyatmi, S., Penerbit Universitas Indonesia, Jakarta.

Martin, A., Swarbrick, J., and Cammarata, A., 1983. Farmasi Fisik. Terjemahan oleh Yoshita, 1993. Jakarta : penerbit UIPress,.

Reiza, Z., 2010, Perbandingan Penggunaan Metode Granulasi Basah dan Granulasi Kering Terhadap Stabilitas Zat Aktif Tablet Paracetamol, (online) (http://www.scribd.com. diakses 29 maret 2011).

Voigt. R., 1984. Buku Pelajaran Teknologi Farmasi. diterjemahkan oleh Soewandhi, 
S. N., Gadjah Mada University

Press, Yogyakarta.

Zhou, M., and Notari, R.E., 1995.

Influence of $\mathrm{pH}$, Temperature, and Buffers on The Kinetics of

Ceftazelime Degradation in

Aqueus Solution. J.Pharm.Sci. 